\title{
Características sociodemográficas e clínicas de pacientes com o vírus da imunodeficiência humana
}

\author{
Sociodemographic and clinical characteristics of patients with human immunodeficiency \\ virus
}

Wesley Romário Dias Martins ${ }^{1}$, Andréa Pereira da Silva ${ }^{2}$, Fabiano de Araujo Silva ${ }^{1}$, Jayra Adrianna da Silva Sousa ${ }^{2}$, Joélio Pereira da Silva ${ }^{3}$, Maria Luzinete Rodrigues da Silva²

\begin{abstract}
Objetivo: descrever as características sociodemográficas e clínicas de pacientes diagnosticados com o vírus da imunodeficiência humana. Métodos: estudo descritivo e documental, desenvolvido a partir das informações sociodemográficas e clínicas contidas nas fichas de identificação de 33 pacientes diagnosticados com o vírus da imunodeficiência humana. Os dados foram analisados por meio do programa Statistical Package for the Social Sciences 18 para o cálculo das medidas estatísticas e associação entre variáveis. Resultados: em relação às características dos pacientes, a média de idade foi de 42 anos, variando entre 20 e 64 anos, 54,5\% mulheres, casados e com baixa escolaridade, $84,8 \%$ heterossexuais e que se expuseram ao vírus por meio de relação sexual $(\mathrm{p}=0,495)$. Conclusão: percebeu-se que os pacientes com a infecção foram mulheres, jovens, com baixo nível de instrução e com exposição ao vírus pelo contato sexual e multiparcerias desprotegidas.
\end{abstract}

Descritores: HIV; Doenças Sexualmente Transmissíveis; Epidemiologia.

Objective: to describe the sociodemographic and clinical characteristics of patients diagnosed with the human immunodeficiency virus. Methods: this is a descriptive and documentary study, developed from the sociodemographic and clinical information registered in the identification sheets of 33 patients diagnosed with human immunodeficiency virus. Data were analyzed using the Statistical Package for the Social Sciences 18, with calculation of statistical measures and association between variables. Results: regarding the characteristics of the patients, the average age was 42 years, ranging from 20 to 64 years, 54.5\% were women, married and with low level of education, $84.8 \%$ were heterosexual and exposed to the virus through of sexual intercourse $(p=0.495)$. Conclusion: the patients with the infection were women, young, with low education and exposure to the virus due to sexual contact and unprotected sex with multiple partners.

Descriptors: HIV; Sexually Transmitted Diseases; Epidemiology.

\footnotetext{
${ }^{1}$ Faculdade Única de Ipatinga. Ipatinga, MG, Brasil.

${ }^{2}$ Universidade Estadual do Piauí “Campus Doutora Josefina Demes”. Floriano, PI, Brasil.

${ }^{3}$ Faculdade de Ensino Superior de Floriano. Floriano, PI, Brasil.
} 


\section{Introdução}

As Infecções Sexualmente Transmissíveis (ISTs) situam-se como agravos à saúde frequentes e prevalentes, transmitidas principalmente pelo contato sexual, em suas diversas modalidades, e causadas, principalmente, por vírus, bactérias ou outros microrganismos $^{(1)}$. Nesse universo, destaca-se o Vírus da Imunodeficiência Humana (HIV) e a Síndrome da Imunodeficiência Adquirida (AIDS) que apesar de serem doenças antigas, oriundas na década de 80 , até o momento, são consideradas problemas de saúde pública e de bem-estar social. Tendo em vista os impactos da infecção nos diversos níveis de atenção à saúde, sua ocorrência não é restrita, podendo acometer todos os indivíduos, sem qualquer distinção( ${ }^{(2)}$.

Dados recentes sobre a temática mostraram que no mundo cerca de 37,9 milhões de pessoas vivem com HIV. Já a nível nacional, a situação das notificações também chama atenção, visto que foram identificados, no Brasil, de 2007 até junho 2018, 247.795 casos, sendo a maioria em pessoas do sexo masculino, na razão de 26 homens para cada 10 mulheres ${ }^{(3)}$. A exposição de forma acentuada a situações de risco os coloca como o grupo mais propenso à infecção.

O perfil clínico dos casos positivos, evidenciado pela literatura, corrobora com os achados supracitados, ao afirmar a prevalência dessa condição clínica na população masculina. Entretanto, um dos agravantes da infecção entre o público feminino é o período gestacional devido às chances de transmissão vertical cujas taxas variam de 25 a 30,0\% quando não existe qualquer tratamento durante o período gravídico e após o mesmo ${ }^{(4)}$.

O cenário de adoecimento perante a epidemia se modificou ao longo dos anos, atualmente os grupos suscetíveis a mais da metade de todas as novas infecções compreendem as pessoas que usam drogas, aquelas privadas de liberdade, homens homoafetivos e outros que fazem sexo ente si, os transgêneros e profissionais do $\operatorname{sexo}^{(5)}$.

A vulnerabilidade e o modo de exposição à doença na população ocorrem de forma distinta, todavia estudos sugerem que a principal forma ainda é a relação sexual desprotegida, com prevalência expressiva em pessoas heterossexuais e no contexto de união estável. Ademais, o principal motivo apontado para não utilizar o preservativo no ato sexual é a confiança no parceiro e também a preferência pessoal em não utilizar ${ }^{(6-7)}$.

A partir das evidências reportadas pelos estudos, emanou-se a seguinte indagação: Qual o perfil sociodemográfico e clínico dos pacientes HIV positivos diagnosticados em um centro de referência em testes sorológicos? A produção de conhecimentos sobre as características clínicas dessa população pode favorecer a elaboração e aplicação de medidas preventivas, voltadas à promoção da saúde, assim como o controle da doença.

A relevância da pesquisa justifica-se pelo fato dessa infecção ser um grande desafio para os serviços de saúde e profissionais da área em razão da elevada prevalência e pela necessidade de conhecer os aspectos sociodemográficos e clínicos desses pacientes, visto que, apesar da vulnerabilidade de alguns grupos, ainda existem variações no perfil da epidemia, suscitando constante vigilância e atenção desses aspectos. Diante disso, a presente investigação teve como objetivo descrever as características sociodemográficas e clínicas de pacientes diagnosticados com o vírus da imunodeficiência humana.

\section{Métodos}

Trata-se de um estudo documental descritivo e quantitativo, realizado em um Centro de Testagem e Aconselhamento, situado no município de Floriano, Piauí, Brasil. A amostra foi composta pelas fichas de identificação dos pacientes diagnosticados com HIV, que deram entrada na referida instituição, no período de janeiro a dezembro de 2017.

A população foi composta inicialmente por 41 formulários de pacientes com diagnóstico positivo para o HIV, quando se empregaram os critérios de in- 
clusão e exclusão, foi possível descartar 8 formulários, obtendo-se, dessa forma, uma amostra de 33 pacientes com diagnósticos positivos para a infecção.

Utilizaram-se como critérios de inclusão os formulários de entrada devidamente preenchidos, contendo as informações sociodemográficas e clínicas dos pacientes. Foram excluídos os formulários que não contemplaram o período de estudo ou que estivessem ilegíveis.

A coleta de dados ocorreu entre março e abril de 2018, norteada por um instrumento semiestruturado elaborado pelos autores, dividido em duas partes, correspondentes aos dados sociodemográficos e às variáveis clínicas comportamentais relacionadas à exposição ao vírus.

As informações sociodemográficas consideradas para análise neste estudo incluíram sexo, idade, estado civil, escolaridade e orientação sexual. Já as variáveis clínicas investigadas foram o tipo de exposição ao vírus, quantidade de parceiros sexuais no último ano, bem como uso de preservativo com parceiro fixo e contato com outras ISTs.

Após coleta dos dados, estes foram organizados e colocados em planilha do Microsoft Excel 2016, sendo duplamente digitados pelos autores a fim de evitar erros e viés na pesquisa. Logo depois, houve a transferência para o programa Statistical Package for the Social Sciences 18 para o cálculo das medidas estatísticas médias e desvio padrão. Para os cruzamentos das variáveis, utilizou-se o teste Exato de Fisher. A variável dependente utilizada nas associações foi o sexo e como independente elencaram-se as características clínicas relacionadas à vulnerabilidade ao HIV. Na análise, foram consideradas como significantes aquelas com $\mathrm{p}<0,05$.

Anteriormente ao início da coleta, cabe salientar que foi disponibilizado na instituição participante o documento legal que respalda a utilização de dados a fim de respeitar o sigilo das informações fornecidas e preservar todos os aspectos éticos preconizados pela normativa nacional que se reporta aos estudos envolvendo seres humanos. A pesquisa foi aprovada pelo Comitê de Ética e Pesquisa da Universidade Estadual do Piauí por meio do Certificado de Apresentação para Apreciação Ética no 84179318.6 .0000 .5209 e parecer de aprovação de no 2.537.165/2018.

\section{Resultados}

Dos 33 formulários investigados no estudo, foi possível identificar na Tabela 1 que a média de idade dos pacientes com diagnósticos positivos para o HIV situou-se em 42 anos, variando entre 20 e 64 anos. Houve predomínio de mulheres, 18 (54,5\%); casados ou em união estável, 22 (66,7); cerca de 18 $(54,5 \%)$ eram analfabetos ou estudaram apenas o ensino fundamental; e heterossexuais em sua maioria, $28(84,8 \%)$.

Tabela 1 - Características sociodemográficas dos pacientes com o vírus da imunodeficiência humana

\begin{tabular}{lc}
\hline Variáveis & n (\%) \\
\hline Sexo & $18(54,5)$ \\
Feminino & $15(45,5)$ \\
Masculino & \\
Idade (anos) & $10(30,3)$ \\
20 a 29 & $18(54,5)$ \\
30 a 49 & $4(12,2)$ \\
50 a 59 & $1(3,0)$ \\
$>60$ & \\
Estado civil & $9(27,3)$ \\
Solteiro & $22(66,7)$ \\
Casado/União estável & $2(6,0)$ \\
Viúvo & \\
Escolaridade & $4(12,1)$ \\
Analfabeto & $14(4,0)$ \\
Ensino fundamental completo/incompleto & $14(42,4)$ \\
Ensino médio completo/incompleto & $15(45,5)$ \\
Orientação sexual & \\
Heterossexual & \\
Homossexual & \\
Bissexual & \\
\hline
\end{tabular}


No que diz respeito às variáveis clínicas, percebeu-se um cenário elevado de risco de infecção, visto que $26(78,8 \%)$ dos pacientes contraíram o vírus por meio de relação sexual, $25(75,8 \%)$ relataram ter se relacionado sexualmente no último ano com um parceiro e nunca terem usado preservativo com parceiro fixo, 20 (60,6\%). A maioria não contraiu algum tipo de IST no último ano, 23 (69,7\%) (Tabela 2).

Tabela 2 - Características clínicas dos pacientes com o vírus da imunodeficiência humana

\begin{tabular}{lc}
\hline Variáveis & n (\%) \\
\hline Tipo de exposição ao vírus & \\
Relação sexual & $26(78,8)$ \\
Transfusão de sangue & $1(3,0)$ \\
Outros & $6(18,2)$ \\
№ de parceiros sexuais no último ano & \\
1 & $25(75,8)$ \\
2 a 4 & $4(12,1)$ \\
$>5$ & $4(12,1)$ \\
Uso de preservativo com parceiro fixo & \\
Nunca & $20(60,6)$ \\
Às vezes & $11(33,3)$ \\
Não informado & $2(6,1)$ \\
Contraiu algum tipo de Infecção Sexualmente & \\
Transmissível no último ano & $7(21,2)$ \\
Sim & $23(69,7)$ \\
Não & $3(9,1)$ \\
\hline
\end{tabular}

Em relação às associações entre as variáveis clínicas e o sexo dos pacientes, observou-se que metade dos homens e das mulheres teve exposição ao HIV por meio de relação sexual $(\mathrm{p}=0,495)$. 0 maior número de parcerias sexuais no último ano foi entre os homens $(\mathrm{p}=0,156)$. Quanto ao uso do preservativo com parceiro fixo, $13(65,0 \%)$ das mulheres relataram nunca utilizar $(\mathrm{p}=0,307)$ e $4(57,1 \%)$ contraíram algum tipo de IST no último $(\mathrm{p}=0,741)$, conforme Tabela 3 .
Tabela 3 - Associações entre as variáveis clínicas e o sexo dos pacientes

\begin{tabular}{|c|c|c|c|}
\hline \multirow[b]{2}{*}{ Variáveis } & \multicolumn{2}{|c|}{ Sexo } & \multirow[b]{2}{*}{$\mathbf{p}^{*}$} \\
\hline & $\begin{array}{c}\text { Feminino } \\
\text { n (\%) }\end{array}$ & $\begin{array}{c}\text { Masculino } \\
\text { n (\%) }\end{array}$ & \\
\hline Tipo de exposição ao vírus & & & 0,495 \\
\hline Relação sexual & $13(50,0)$ & $13(50,0)$ & \\
\hline Transfusão de sangue & $1(100,0)$ & - & \\
\hline Outros & $4(66,7)$ & $2(33,3)$ & \\
\hline № de parceiros sexuais no último ano & & & 0,156 \\
\hline 1 & $9(36,0)$ & $16(64,0)$ & \\
\hline 2 a 4 & $1(25,0)$ & $3(75,0)$ & \\
\hline$>5$ & $1(25,0)$ & $3(75,0)$ & \\
\hline Uso de preservativo com parceiro fixo & & & 0,307 \\
\hline Nunca & $13(65,0)$ & $7(35,0)$ & \\
\hline Às vezes & $4(36,4)$ & $7(63,6)$ & \\
\hline Não informado & $1(50,0)$ & $1(50,0)$ & \\
\hline $\begin{array}{l}\text { Contraiu algum tipo de Infecção Se- } \\
\text { xualmente Transmissível no último } \\
\text { ano }\end{array}$ & & & 0,741 \\
\hline Sim & $4(57,1)$ & $3(42,9)$ & \\
\hline Não & $13(56,5)$ & $10(43,5)$ & \\
\hline Não informado & $1(66,7)$ & $2(33,3)$ & \\
\hline
\end{tabular}

\section{Discussão}

Dentre as limitações do estudo, destaca-se a composição da amostra, limitada devido ao período investigado ser apenas de um ano e às perdas relacionadas à incompletude de algumas fichas de identificação dos pacientes, impossibilitando, assim, a análise de demais casos. Contudo, foi possível verificar a dinâmica do perfil de exposição à infecção na população, instigando, dessa forma, a utilização de novas abordagens na assistência à saúde que pontuem as singularidades clínicas e a vulnerabilidade dos indivíduos.

0 presente estudo evidenciou que as mulheres representam a maior população diagnosticada como HIV, em comparação ao sexo masculino. De forma distinta, dados internacionais e nacionais mostram que existem mais casos da doença entre os homens, mas a proporção tem diminuído ao longo dos anos, observando-se o aumento dos casos em pessoas do sexo 
feminino $^{(3,5)}$. Esse cenário chama atenção e pondera a importância de implementar medidas preventivas, voltadas para ambos os sexos, pois, apesar da existência de uma população mais exposta, o perfil de adoecimento e contato com o vírus é distinto.

Quanto à idade dos pacientes, houve predominância entre os jovens, demonstrando, assim, tendência à juvenilização dos casos. A prevalência nesse grupo pode ser explicada pelo comportamento de risco vivenciado, principalmente em relação à multiparceria sexual, não utilização da camisinha, realizar o ato sexual, ocasionalmente, com pessoas esporádicas ao mesmo tempo em que consome drogas lícitas ou ilícitas $^{(8)}$. Provavelmente, nesse período da vida, a maioria da população encontra-se sexualmente ativa e em plena idade reprodutiva, constituindo, assim, o grupo etário de maior risco de incidência da doença.

No que concerne ao estado civil, observou-se que o maior número de notificações do HIV foi entre os casados ou em união estável. Achados semelhantes foram observados em uma pesquisa realizada com pessoas que apresentavam sorologia positiva para o HIV, internadas em um serviço de saúde, referência em doenças infecciosas, no qual $63,8 \%$ dos pacientes estudados eram casados $^{(9)}$.

Os dados supracitados confirmam o fato de casais que possuem união estável tendem a não utilizar métodos contraceptivos de barreira, ficando, dessa forma, mais propensos às infecções sexualmente transmissíveis, como o HIV ${ }^{(10)}$.

Em se tratando de escolaridade, a maioria da população do estudo era analfabeta ou possuía o ensino fundamental incompleto/completo. 0 aspecto escolar, principalmente relacionado ao pouco acesso de algumas pessoas, ao contexto do ensino e aprendizagem, pode contribuir para a falta de conhecimento, acesso e entendimento das informações em saúde, pertinentes a esse agravo. Logo, os indivíduos que têm um grau maior de instrução tendem a compreender melhor as demandas exigidas na prevenção dessa infecção ${ }^{(11-12)}$.

A literatura evidencia que realmente $o$ acesso a níveis elevados de ensino traz repercussões positivas sobre a saúde, pois as pessoas que se situam nesse grupo têm a possibilidade de obter, de forma facilitada, o conhecimento sobre a doença, empoderando-se das ações preventivas cabíveis nesse contexto, principalmente em relação à exposição ao vírus, visto que é esperado que exerçam comportamentos isentos de risco, levando em consideração a ciência destes perante os impactos causados pela doença ${ }^{(13)}$. Diante desse quadro, a assistência em saúde prestada aos mais diversos públicos deve considerar os aspectos educacionais dos indivíduos para que seja realmente efetiva.

Na presente investigação, os heterossexuais foram os mais acometidos com a infecção, corroborando com outras pesquisas que afirmam que, a partir da década de 90, o perfil epidemiológico se modificou e a principal via de transmissão passou a ser a heterossexual, de homem para mulher ou vice- versa, o que aumentou significativamente o número de heterossexuais com esse agravo ${ }^{(14-15)}$.

No que se refere ao tipo de exposição ao vírus, uma grande proporção dos pacientes contraiu a infecção por meio de relação sexual. Outros estudos também apontaram esse modo de transmissão como recorrente em parte dos casos investigados e que as informações relacionadas à proteção sexual e à vulnerabilidade ainda são ignoradas pelos indivíduos ${ }^{(3)}$.

Quanto ao número de parceiros sexuais no último ano, a maioria dos homens manteve relação com mais de um parceiro, já as mulheres relataram, em grande parte dos casos, nunca ter utilizado preservativo com parceiro fixo. Uma pesquisa realizada com 1.222 mulheres em Pelotas, no Sul do Brasil, trouxe resultados que ratificam os achados da presente investigação, ao elencar o perfil e as vivências comportamentais de mulheres que realizaram o exame anti-HIV. Os autores constataram que $56,9 \%$ tinham companheiro fixo e $64,7 \%$ não utilizavam preservativo em suas práticas sexuais ${ }^{(6)}$. Tal fato expõe o comportamento de risco vivenciado por algumas mulheres em adquirir as ISTs $^{(16)}$. 
Outro estudo, dessa vez realizado em Cuba, identificou a desigualdade de gênero como uma barreira social nas práticas de vida sexual segura e protegida. Além disso, a baixa percepção de risco é uma barreira na decisão de usar um preservativo, em mulheres que têm um parceiro estável, casadas ou não porque não veem a necessidade de se proteger ${ }^{(17)}$.

Assim, as práticas de saúde desenvolvidas pelos profissionais, principalmente, em âmbito primário, devem voltar-se às diversas linhas da promoção da saúde, pautadas, sobremaneira, perante o incentivo do sexo seguro, com a proteção nas relações sexuais, tanto para método contraceptivo quanto para prevenção dos agravos sexualmente transmissíveis, em ambos os gêneros.

A literatura aponta, ainda, que entre as principais justificativas das mulheres para não utilizar preservativos em suas relações sexuais está a confiança no parceiro e também a preferência pessoal de absterse do uso ${ }^{(6)}$. Nesse sentido, é imperativo um olhar crítico diante dessa dinâmica comportamental feminina, visto a necessidade de romper os desfechos negativos decorrentes da exposição ao vírus.

No que diz respeito ao contato com outras infecções no último ano, o grupo das mulheres foi o que obteve a maior incidência. As estatísticas atuais evidenciam que apesar do decréscimo dos casos de HIV, na população geral, ainda existe um número alarmante de jovens mulheres que adquirem a doença, semanalmente, 6.200 pessoas do sexo feminino são acometidas. Salienta-se que a exposição a esse agravo abre portas para outras infecções, principalmente aquelas transmitidas por via sexual ${ }^{(5,18)}$

Evidências apontam que a prevalência da infecção entre o público feminino tem relação direta com as diferenças históricas que existem entres os gêneros. Esse cenário social vivenciado reflete a tendência das mulheres em ignorar ou aceitar passivamente as múltiplas parcerias sexuais do companheiro, a baixa percepção sobre métodos contraceptivos de barreiras que são simples, acessíveis e disponibilizados gratuitamente e que poderia favorecer sua autonomia, a exemplo da camisinha feminina. Tais fatos suscitam falhas quanto ao acesso e uso dos serviços de testagem por essa população( ${ }^{(19)}$.

\section{Conclusão}

Os resultados encontrados durante o estudo demonstram que a maioria dos pacientes com HIV são mulheres, jovens, casados, com baixo nível de instrução, heterossexuais, com multiparcerias sexuais, sendo a relação sexual o principal meio de exposição à infecção.

\section{Agradecimentos}

À Universidade Estadual do Piauí e ao Centro de Testagem e Aconselhamento pela disponibilidade, oportunidade e apoio durante a realização da pesquisa.

\section{Colaborações}

Martins WRD, Silva AP e Silva MLR contribuíram com a concepção do projeto, coleta e análise de dados, redação e revisão crítica relevante do conteúdo intelectual e aprovação final da versão a ser publicada. Silva FA, Sousa JAS e Silva JP colaboraram na análise dos dados e revisão crítica relevante do conteúdo intelectual.

\section{Referências}

1. Ministério da Saúde (BR). Secretaria de Vigilância em Saúde. Departamento de DST, Aids e Hepatites Virais. Protocolo clínico e diretrizes terapêuticas para manejo da infecção pelo HIV em adultos [Internet]. 2018 [citado 2019 set. 24]. Disponível em:http://www.aids.gov.br/pt-br/pub/2013/ protocolo-clinico-e-diretrizes-terapeuticas-paramanejo-da-infeccao-pelo-hiv-em-adultos

2. Dantas MS, Abrão FMS, Costa SFG, Oliveira DC. HIV/AIDS: meanings given by male health professionals. Esc Anna Nery. 2015; 19(2):323-30. doi: http://dx.doi.org/10.5935/1414-8145.20150044 
3. Ministério da Saúde (BR). Secretaria de Vigilância em Saúde. Departamento de DST, Aids e Hepatites Virais. Boletim Epidemiológico: aids e DST [Internet]. 2018 [citado 2019 set. 12]. Disponível em: http://www. http://www.aids.gov.br/pt-br/ pub/2018/boletim-epidemiologico-hivaids-2018

4. Jordão BA, Espolador GM, Sabino AMNF, Tavares BB. Conhecimento da gestante sobre o HIV e a transmissão vertical em São José do Rio Preto, São Paulo, Brasil. Rev Bras Pesq Saúde [Internet]. 2016 [citado 2019 fev. 20]; 18(2):26-34. Disponível em: http://periodicos.ufes.br/RBPS/article/ download/15081/10683

5. World Health Organization. United Nations Programme on HIV/AIDS. Communities at the centre [Internet]. 2019 [cited set 24, 2019]. Available from: http://www.unaids.org/sites/default/files/ media_asset/2019-global-AIDS-update_en.pdf

6. Mesenburg MA, Wehrmeister FC, Silveira MF. Voluntary versus health professional-initiated HIV testing: a population-based study in women in a city in Southern Brazil. Cad Saúde Pública. 2017; 33(10):e00074415. doi: http://dx.doi.10.1590/ 0102-311X00074415

7. Oliveira TMF, Andrade SSC, Matos SDO, Oliveira SHSO. Risk behavior and self-perceived vulnerability to STIs and AIDS among women. Rev Enferm UFPE on line [Internet]. 2016 [cited Sep. 13, 2019]; 10(1):137-42. Available from: https:// periodicos.ufpe.br/revistas/revistaenfermagem/ article/view/10931

8. Sales WB, Caveião C, Visentin A, Mocelin D, Costa PM, Simm EB. Comportamento sexual de risco e conhecimento sobre IST/SIDA em universitários da saúde. Rev Enferm Ref. 2016; 4(10):19-27. doi: http://dx.doi.org/10.12707/RIV16019

9. Souza Neto VL, Silva RAR, Rocha CCT, Costa RTS, Nóbrega MML. ICNP $®$ nursing diagnoses for people with acquired immunodeficiency syndrome. Acta Paul Enferm. 2017; 30(6):573-81. doi: http:// dx.doi.org/10.1590/1982-0194201700081

10. Paes ALV, Gomes HG, Ribeiro ARS, Lima MMB, Araújo BB, Smith NA. Perfil epidemiológico de gestantes com HIV acompanhadas em um serviço de assistência especializada em Belém-PA. Rev Interdisciplinar [Internet]. 2017 [citado 2019 mar. 10]; 10(3):100-9. Disponível em: https:// revistainterdisciplinar.uninovafapi.edu.br/index. php/revinter/article/view/1313

11. Foresto JS, Melo ES, Costa CRB, Antonini M, Gir E, Reis RK. Adherence to antiretroviral therapy by people living with HIV/AIDS in a municipality of São Paulo. Rev Gaúcha Enferm. 2017; 38(1):e63158. doi: http://dx.doi. org/10.1590/1983-1447.2017.01.63158

12. Patterson S, Carter A, Nicholson V, Webster K, Ding E, Kestler $\mathrm{M}$, et al. Condom less sex among virally suppressed women with HIV with regular HIV-serodiscordant sexual partners in the era of treatment as prevention. J Acquir Immune Defic Syndr. 2017; 76(4):372-81. doi: http://dx.doi. org/10.1097/QAI.0000000000001528

13. Lima SKSS, Sousa KKB, Dantas SLC, Rodrigues ARM, Rodrigues IR. Caracterização das gestantes com HIV/Aids admitidas em hospital de referência. SANARE [Internet]. 2017 [citado 2019 mar. 15]; 16(1):45-51. Disponível em: https://sanare. emnuvens.com.br/sanare/article/view/1093

14. Carrara GLR, Silva AC, Neves MNM, Pereira RS. AIDS em mulheres e o cuidado da enfermagem: uma revisão da literatura. Rev Fafibe On-line [Internet]. 2015 [citado 2019 set. 13]; 8(1):64-85. Disponível em: http://unifafibe.com.br/revistasonline/arquivos/revistafafibeonline/sumario/36/30102015183529.pdf

15. Abreu SR, Pereira BM, Silva NM, Moura L.RP, Brito CMS, Câmara JT. Estudo epidemiológico de pacientes com infecção pelo vírus da imunodeficiência humana/síndrome da imunodeficiência adquirida (HIV/Aids), Caxias- MA. Rev Interdisciplinar [Internet]. 2016 [citado 2019 set. 13]; 9(4):13241. Disponível em: https://revistainterdisciplinar. uninovafapi.edu.br/index.php/revinter/article/ view/1227

16. Barbosa BLFA, Marques AK, Guimarães JV. HIV positive pregnancies and the risk factors related to HIV vertical. Rev Enferm UFPE on line [Internet]. 2018 [cited Sep. 13, 2019]; 12(1):171-8. Available from:https://periodicos.ufpe.br/revistas/ revistaenfermagem/article/view/23257

17. Gutiérrez MRB. Barriers to access and use of the condom from a gender perspective. Horizonte Sanitário. 2019; 18(1):67-74. doi: http://10.19136/ hs.a18n1.2306 
18. Ministério da Saúde (BR). Secretaria de Vigilância em Saúde. Departamento de DST, Aids e Hepatites Virais. Protocolo Clínico e Diretrizes Terapêuticas para Atenção Integral às Pessoas com Infecções Sexualmente Transmissíveis [Internet]. 2015 [citado 2019 set. 12]. Disponível em: http://bvsms.saude.gov.br/bvs/publicacoes/protocolo_clinico_diretrizes_terapeutica_atencao_integral_pessoas_infeccoes_sexualmente_transmissiveis.pdf
19. Lima RR, Santos MJL, Lira MCC, Mangueira SO, Damásio SLC. Perfil epidemiológico de la infección por HIV/AIDS relacionado a la actividad ocupacional. Rev Enferm UFPE on line [Internet]. 2015 [cited Sep. 13, 2019]; 9(Supl. 4):8012-8. Available from: https://periodicos.ufpe.br/revistas/revistaenfermagem/article/viewFile/10554/11477 